\title{
Publisher Correction: Symmetry and magnetism allied
}

Manfred Fiebig

Correction to: Nature Materials https://doi.org/10.1038/s41563-018-0113-6, published online 18 June 2018.

In the version of this News \& Views originally published, the placement of the white circle in Fig. 1 was in the wrong position; it should have been over the six-domain vortex. This has now been corrected. The original and corrected figures are shown below.
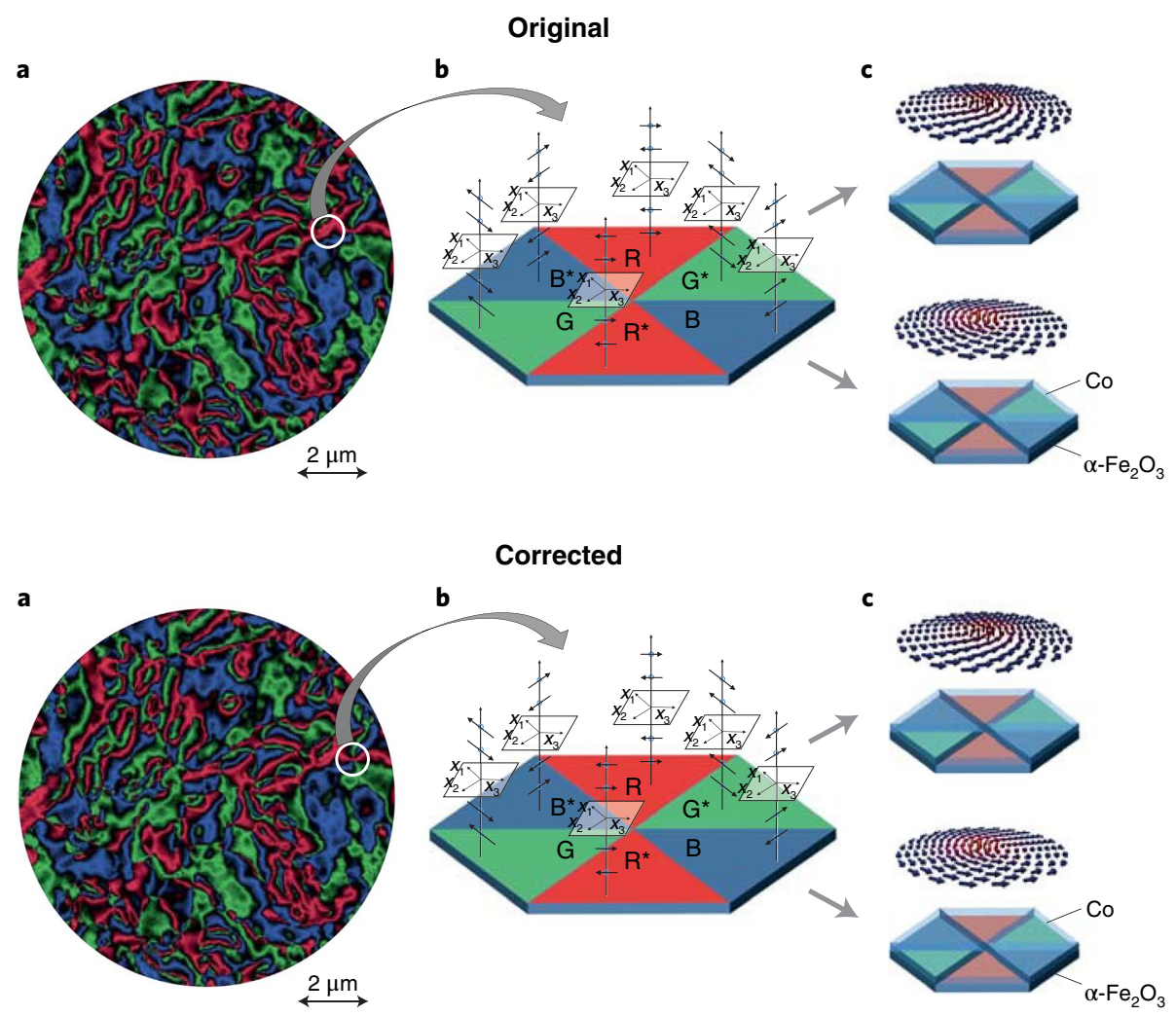

Fig. 1 | Original and corrected.

Published online: 9 July 2018

https://doi.org/10.1038/s41563-018-0145-y 